\title{
lodine status of pregnant women in Sri Lanka
}

\author{
Renuka Jayatisa' ${ }^{1}$ M M Gunathilaka ${ }^{1}$, J M Ranbanda' ${ }^{1}$ P Peiris ${ }^{1}$, J Jayasingha' ${ }^{1}$ P Ekanayaka ${ }^{1}$, \\ H Kulathunga $^{1}$
}

Sri Lanka Journal of Diabetes, Endocrinology and Metabolism 2013; 3: 4-7

\begin{abstract}
Based on new evidence and lessons learned within the last decade, pregnant women may not receive adequate iodized salt where the coverage of universal salt iodisation is poor. World Health Organisation has stated this could jeopardize optimal brain development of the fetus. This study was aimed to assess the iodine status of pregnant women in Sri Lanka. A cross-sectional clinic based nationally representative study was conducted. Three randomly selected antenatal clinics from each province, 30 randomly selected pregnant women from each selected clinic were included in the study. A total of 739 pregnant women were studied and casual urine samples collected to estimate iodine levels. Median urinary iodine levels in pregnant women was $113.7 \mathrm{~g} / \mathrm{L}$, which is far below the WHO recommendation between 150 and 249 $\mu \mathrm{g} / \mathrm{L}$ indicating inadequate iodine status of pregnant women in Sri Lanka. Urine iodine distribution indicated $61.3 \%, 21.7 \%, 15.2 \%$ and $1.8 \%$ of pregnant women had an inadequate, adequate, above requirement and excessive intake respectively. Urinary iodine concentration significantly decreased with advancing pregnancy. Inadequate iodine intake was evident in $47.4 \%, 60.2 \%$ and $68.8 \%$ of pregnant women in the first, second and third trimester respectively. In conclusion, there is an urgent need to identify a programme to provide adequate iodine to pregnant women to ensure optimum fetal brain development.
\end{abstract}

\section{Introduction}

Iodine is an essential trace element that is an integral component required for the prevention of brain damage and mental retardation. Iodine deficiency is one of the world's most preventable diseases, that is both easy and inexpensive to avert (1). Iodine deficiency disorders was identified as a major public health problem and the Universal Salt Iodisation (USI) programme was launched in Sri Lanka in 1995 in collaboration with UNICEF (2).

Maternal iodine deficiency is associated with a number of adverse effects on the infant brain resulting in a continuum of effects depending on the degree of iodine deficiency, from lowered IQ to severe mental retardation. The thyroid gland uses iodine to make thyroid hormones, which in turn directs brain development. Iodine deficiency in pregnant women has been estimated to result in the loss of some 10-15 IQ points at the global population level (3).

Urinary iodine excretion is a useful and important indicator of the iodine status of a population. The World Health Organization (WHO) recommends that the median urinary iodine concentration in a population of pregnant women should range between 150 and $249 \mu \mathrm{g} / \mathrm{L}$ and among school children 100 and $200 \mu \mathrm{g} / \mathrm{L}$ (4).
It has been shown that in some countries, although iodine intake is sufficient in school-age children, there is iodine deficiency in pregnant women (5). This finding justifies the need for a continuous monitoring of iodine nutrition in these two vulnerable populations. In Sri Lanka, there are no national level data regarding urinary iodine concentration (UIC) in pregnant women, after the implementation of USI program.

Hence, this study was conducted to determine the iodine nutritional status by measuring urinary iodine in pregnant women.

\section{Methods}

This was a cross sectional, nationally representative study. The study population was identified as pregnant women. The required sample size was calculated considering the $50 \%$ iodine sufficiency among pregnant women, $5 \%$ precision with design effect of 1.7 and $10 \%$ of non response rate. The calculated sample size was 810 . This was a clinic-based study conducted as a part of a national iodine survey.

When the field investigators visited a randomly selected school in the province for the national study, they were advised to visit the closet antenatal clinic to obtain urine samples from pregnant women. Thirty

${ }^{1}$ Medical Research Institute, Ministry of Health, Colombo, Sri Lanka. 
pregnant women were selected using the clinic register and casual urine samples were obtained with the assistance of the public health staff in the respective area (6). It was transported to the Medical Research Institute (MRI) laboratory for analysis. Data collection was done from November 2010 to January 2011.

The urine samples were labelled and stored in large plastic containers and then transported for storage at 4$8^{\circ} \mathrm{C}$. They were transported to the national laboratory with cold packs and stored at $-20^{\circ} \mathrm{C}$ until analysis. Modified microplate method was used to assess urine iodine concentration (7). Internal quality control analysis was carried out throughout, by using samples with known iodine values. External quality control was carried out in collaboration with the Center of Disease Control (CDC) Laboratory in Atlanta as a partner of the quality control programme.

Data entry and analysis was carried out using the EPI/INFO and SPSS 16.0 software packages. Ethical clearance was obtained from the Ethical Committee of MRI and permission was obtained from the relevant educational and health authorities.

\section{Results}

A total of 739 pregnant women participated in the study. The response rate was $91.2 \%$. The median duration of pregnancy was 24 weeks, ranging from 5 to 40 weeks.

Figure 1 shows the distribution of urinary iodine concentrations (UIC) which was shifted to the left of the normal curve. Median UIC of pregnant women was 115.0 $\mu \mathrm{g} / \mathrm{L}$ ranging from 3.5 to $720.2 \mu \mathrm{g} / \mathrm{L}$, which is far below the level recommended by the WHO for pregnant women (150$249 \mu \mathrm{g} / \mathrm{L})$.

Table 1 describes the UIC of pregnant women, by provinces. In the majority of provinces except in Northern, Eastern and North Central provinces, the median UIC was below the cut-off point of $150 \mu \mathrm{g} / \mathrm{L}$ indicating iodine intake in pregnant women in these provinces was not optimum. There was a significant inter provincial variation of UIC in pregnant women; highest in the North Central and lowest in the Sabaragamuwa province.

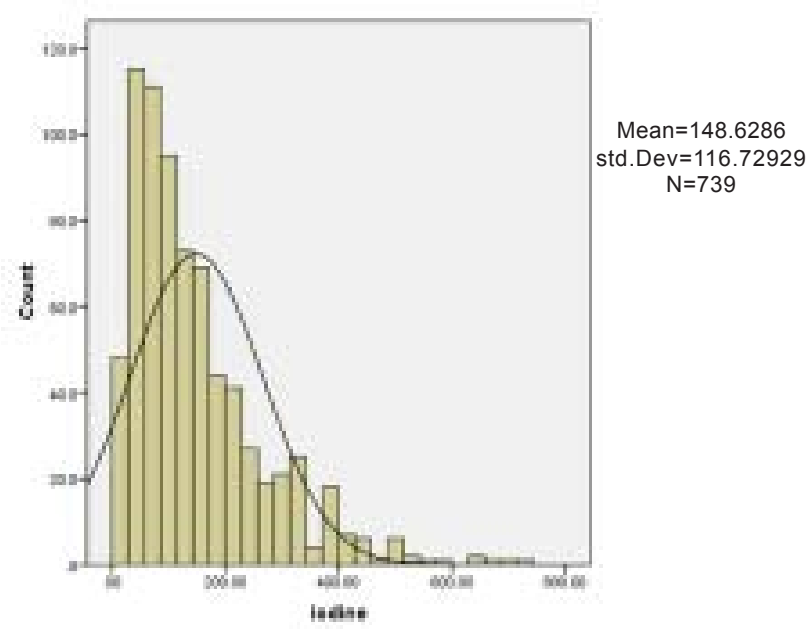

Figure 1. Distribution pattern of urinary iodine values in pregnant women.

Table 1. Urinary iodine levels of pregnant women by provinces

\begin{tabular}{lccc}
\hline Province & Total number examined & Urinary iodine concentration $(\mu g / L)$ \\
\cline { 3 - 4 } & & Median & Range \\
\hline Western & 86 & 128.5 & $18.6-530.9$ \\
Central & 79 & 85.2 & $10.3-508.6$ \\
Southern & 88 & 87.7 & $3.5-694.0$ \\
Northern & 81 & 154.4 & $33.4-526.5$ \\
Eastern & 87 & 165.9 & $11.3-720.2$ \\
North Western & 81 & 133.5 & $32.5-441.1$ \\
North Central & 73 & 167.2 & $23.5-427.9$ \\
Uva & 78 & 83.7 & $6.5-676.5$ \\
Sabaragamuwa & 86 & 72.3 & $10.6-426.5$ \\
Sri Lanka & 739 & $\mathbf{1 1 3 . 7}$ & $3.5-\mathbf{7 2 0 . 0}$ \\
\hline
\end{tabular}

$(\mathrm{F}=7.7, \mathrm{P}=0.000)$ 
Table 2 shows the frequency distribution of UIC of pregnant women by provinces. In the entire sample, $21.7 \%$ of pregnant women had urine iodine at an adequate level $(150-249 \mu \mathrm{g} / \mathrm{L})$. Of the total sample, $61.4 \%$ of pregnant women had inadequate iodine level $(<150 \mu \mathrm{g} / \mathrm{L}$ urine iodine) and $15.2 \%$ had above the requirement of urinary iodine levels (250-499 g/L). About 1.8\% pregnant women had excessive iodine intake $(>=500 \mu \mathrm{g} / \mathrm{L})$. The proportion of pregnant women with inadequate
UIC significantly varied between provinces; highest being the Sabaragamuwa and lowest in the Eastern province.

When the median UIC between each trimester was compared, there were significant differences ( $p>0.05)$. It is interesting to note that a significantly decreasing pattern of the median UIC occurs with an increasing period of amenorrhoea (Table 3).

Table 2. Frequency distribution of urine iodine levels by provinces

\begin{tabular}{|c|c|c|c|c|c|}
\hline \multirow[t]{2}{*}{ Province } & \multirow[t]{2}{*}{ No. } & \multicolumn{4}{|c|}{ Percentage of urine iodine levels $(\mu g / L)$} \\
\hline & & $\begin{array}{c}<150 \\
\text { Insufficient }\end{array}$ & $\begin{array}{l}150-249 \\
\text { Adequate } \\
\text { requirement }\end{array}$ & $\begin{array}{c}\text { 250-499 } \\
\text { Above }\end{array}$ & $\begin{array}{c}\geq 500 \\
\text { Excessive }\end{array}$ \\
\hline Western & 86 & 55.8 & 22.1 & 18.6 & 3.5 \\
\hline Central & 79 & 75.9 & 15.2 & 6.3 & 2.5 \\
\hline Southern & 88 & 75.0 & 17.0 & 6.8 & 1.1 \\
\hline Northern & 81 & 48.1 & 24.7 & 25.9 & 1.2 \\
\hline Eastern & 87 & 44.8 & 23.0 & 28.7 & 3.4 \\
\hline North Western & 81 & 56.8 & 25.9 & 17.3 & 0.0 \\
\hline North Central & 73 & 47.9 & 28.8 & 23.3 & 0.0 \\
\hline Uva & 78 & 69.2 & 21.8 & 5.1 & 3.8 \\
\hline Sabaragamuwa & 86 & 77.9 & 17.4 & 4.7 & 0.0 \\
\hline Sri Lanka & 739 & 61.3 & 21.7 & 15.2 & 1.8 \\
\hline
\end{tabular}

$(\mathrm{F}=7.7 ; \mathrm{P}=0.000)$

Table 3. Urinary iodine concentrations (UIC) of pregnant women according to trimester and distribution of concentrations

\begin{tabular}{lcccccc}
\hline $\begin{array}{l}\text { Period of } \\
\text { amenorrhea } \\
\text { (weeks) }\end{array}$ & \multicolumn{2}{c}{$*$ UIC $(\mathrm{g} / \mathrm{L})$} & \multicolumn{4}{c}{$*$ Percentage of urine iodine levels $(\mu \mathrm{g} / \mathrm{L})$} \\
\cline { 2 - 7 } & Median & Range & $\begin{array}{c}<150 \\
\text { Insufficient }\end{array}$ & $\begin{array}{c}150-249 \\
\text { Adequate }\end{array}$ & $\begin{array}{c}250-499 \\
\text { Above } \\
\text { requirement }\end{array}$ & $\begin{array}{c}\geq 500 \\
\text { Excessive }\end{array}$ \\
\cline { 2 - 7 } $1-12(\mathrm{n}=116)$ & 155.3 & $6.5-694.0$ & 47.4 & 26.7 & 23.3 & 2.6 \\
$12.1-28(\mathrm{n}=352)$ & 117.3 & $5.5-720.2$ & 60.2 & 22.7 & 15.9 & 1.1 \\
$>28(\mathrm{n}=269)$ & 100.6 & $3.5-645.5$ & 68.8 & 18.2 & 10.8 & 2.2 \\
All (n=737) & $\mathbf{1 1 3 . 7}$ & $\mathbf{3 . 5 - 7 2 0 . 0}$ & $\mathbf{6 1 . 3}$ & $\mathbf{2 1 . 7}$ & $\mathbf{1 5 . 2}$ & $\mathbf{1 . 8}$ \\
\hline
\end{tabular}

$(* \mathrm{~F}=5.85, \mathrm{P}=0.003 ; * * \mathrm{X} 2=19.3, \mathrm{P}=0.004)$ 


\section{Discussion}

Based on new evidence and lessons learned within the last decade, it appears that the most susceptible groups - pregnant and lactating women, and children less than two years of age - might not be adequately covered by iodized salt where USI is not fully implemented. This situation may jeopardize the optimal brain development of the fetus and young child (4). According to the current WHO/UNICEF/ICCIDD criteria, this study confirms that pregnant women in Sri Lanka, have an insufficient iodine intake.

In 2010 , only $69.4 \%$ of salt at household level contained an adequate iodine concentration of $>15 \mathrm{ppm}$ in Sri Lanka (8). This could contribute to insufficient iodine intake in pregnant women. These data contrast with several countries that analyzed iodine nutrition status in pregnant women (10). On the one hand, it has been shown that insufficient coverage of USI programs fail to achieve optimal iodine nutrition during gestation. WHO has indicated that countries with household access to iodised salt between $20-90 \%$ should make every available effort to accelerate salt iodisation or check the feasibility of increasing iodine intake in the form of a supplement or iodine fortified foods by the most susceptible groups (9).

In contrast, countries such as Switzerland and the United States reach overall optimal iodine nutrition in pregnancy without mandatory salt iodization; however, they have permanent monitoring of iodine nutrition programs in their population, thus allowing the timely implementation of corrective actions. This continuous monitoring has recently revealed that some subgroups of pregnant women in the United States may be at risk of mild iodine deficiency, which further highlights the importance of a permanent surveillance program (11).

There was a significant trend toward a reduction of median UIC from the first to third trimester of gestation, together with a significant increase in the percentage of samples below $150 \mu \mathrm{g} / \mathrm{L}$ of UIC. Other studies in countries such as Bosnia and Herzegovina, Iran and Thailand have shown a similar behavior in the median of UIC in the last two trimesters of gestation (12). This reduction of UIC during pregnancy is more clearly evident in places where iodine intake is borderline sufficient or frankly deficient. These data may suggest a depletion of maternal iodine stores due to a maternal-fetal use, renal elimination, and/ or inadequate dietary compensation.

\section{Conclusions}

There is an inadequate level of iodine intake in pregnant women to be considered as a priority. It is recommended to conduct suitable programmes to achieve the adequate level of iodine in pregnant women.

\section{Acknowledgements}

This study was supported by the UNICEF Colombo. The authors thank P. A. Piyaratna, Principle Public Health Inspector and all the health staff in districts for analyzing the data and for their support in conducting the study. We thank all staff of the Department of Nutrition for supporting the data collection.

\section{References}

1. World Health Organisation, 1994. Iodine and health eliminating iodine deficiency disorders safely through salt iodisation, WHO/NUT/94.4, Geneva.

2. Medical Research Institute, 2001. Iodine nutrition status in Sri Lanka 2000-2001. UNICEF.

3. Andersson M, Benoist B de, Delange F, Zupan J. Prevention and control of iodine deficiency in pregnant and lactating women and in children less than 2-years-old: conclusions and recommendations of the Technical Consultation. Public Health Nutrition 10(12A): 1606-11.

4. WHO. Joint Statement by the World Health Organization and the United Nations Children's Fund. Reaching Optimal Iodine Nutrition in Pregnant and Lactating Women and Young Children, 2007.

5. Anderson M, Takkovche B, Egli I, Allen HE and De Benosit B. Current global iodine status and progress over the last decades towards the elimination of iodine deficiency. Bulletin of the World Health Organisation 2005; 83: 518-525.

6. Sullivan KM, May S. Urinary Iodine Assessment: A Manual on survey and laboratory methods. UNICEF. October 1999; $1-20$.

7. Ohashi T, Yamaki M, Pandav CS, Karmarkar, Irie M. Simple microplate method for determination of urinary iodine. Clinical Chemistry 2000; 46(4): 529-36.

8. Jayatissa R, Gunathilaka MM. Third National Survey on Iodine Deficiency Status in Sri Lanka 2010. UNICEF and Ministry of Health: 2012.

9. http://www.who.int/elena/titles/iodine_pregnancy/en/. Accessed on 03/01/2012.

10. Tananakina N, Kravchenko V, Belkina O, Haar F. Iodine deficiency during pregnancy and infancy in the south-eastern Ukraine. International council for control of iodine deficiency disorders. IDD Newsletter 2011; 39(2).

11. Eduardo AP. ICCIDD, the spark for success in the Americas. International council for control of iodine deficiency disorders. IDD Newsletter 2011; 39(1). 